\title{
ATRIBUTOS FíSICOS DO SOLO EM DIFERENTES REGIMES DE MANEJO EM UM AGROECOSSISTEMA EM IBATIBA/ES
}

\author{
Natan Amurim Ribeiro ${ }^{1}$ \\ Ivan da Costa llhéu Fontan ${ }^{2}$ \\ Arnaldo Henrique de Oliveira Carvalho ${ }^{3}$ \\ Fábio Luiz de Oliveira ${ }^{4}$
}

\begin{abstract}
Resumo: O objetivo do presente estudo foi avaliar atributos físicos do solo na camada de 0 a $40 \mathrm{~cm}$ em locais com diferentes usos em um agroecossistema no municipio de Ibatiba/ES, de maneira a analisar seu sistema de manejo do solo. Foram retiradas amostras de solos deformadas nas camadas de 0-10, 10-20 e 20-40 cm de profundidade em três locais (mata nativa, lavoura de café e pastagem), para determinação da porosidade total, densidade (base gravimétrica) e umidade do solo. Não houve efeito significativo para a interação local $x$ profundidade de coleta, sugerindo que estes fatores agem de maneira independente sobre as variáveis estudadas. A umidade do solo foi estatisticamente inferior na profundidade de $0-10 \mathrm{~cm}$ $(15,10 \%)$, em relação às profundidades $10-20 \mathrm{~cm}(19,13 \%)$ e 20-40 cm (20,61\%). As densidades nos locais pastagem $\left(1,108 \mathrm{~g} \mathrm{~cm}^{-3}\right)$ e café $\left(1,129 \mathrm{~g} \mathrm{~cm}^{-3}\right)$ foram estatisticamente iguais entre si, porém significativamente superiores à área de mata nativa $\left(1,081 \mathrm{~g} \mathrm{~cm}^{-3}\right)$. A avaliação do agroecossistema estudado indicou que as práticas de manejo adotadas favorecem a manutenção da estrutura do solo e sugerem que o sistema utilizado na propriedade tenha condições de garantir a sustentabilidade da produção em longo prazo.
\end{abstract}

Palavras-chave: Agroecossistema; Estrutura do solo; Sistemas de manejo.

\footnotetext{
1 Instituto Federal do Espírito Santo/Campus Ibatiba, Brasil. E-mail: natan.a.r@hotmail.com.

2 Instituto Federal do Espírito Santo/Campus Ibatiba, Brasil. E-mail: ivanfontan.florestal@gmail.com.

3 Instituto Federal do Espírito Santo/Campus Ibatiba, Brasil. E-mail: acarvalho@ifes.edu.br.

${ }^{4}$ Professor - UFES - CCA, Departamento de Produção Vegetal, Brasil. E-mail: fabio.oliveira.2@ufes.br.
} 